\title{
Effect of Dilution Rate and Growth-Limiting Substrate on the Metabolic Activity of Torula utilis Cultures
}

\author{
By D. W. TEMPEST AND D. HERBERT \\ Microbiological Research Establishment, Porton Down, Wiltshire
}

(Received 27 May 1965)

SUMMARY

Torula utilis was grown in a chemostat, at several dilution rates, in media containing growth-limiting concentrations of glucose, xylose and ethanol; it was similarly grown in an $\mathrm{NH}_{4}{ }^{+}$-limited medium (carbon source, glucose). The 'steady state' rates of oxygen uptake of cultures, and $\boldsymbol{Q}_{\mathbf{o}_{2}}$ values for washed suspensions of organisms separated from the cultures and incubated with each substrate, were determined at each dilution rate. Differences in oxidation rates indicated quantitative changes in the 'constitutive' enzyme content of organisms, which varied according to the growth rate and/or the nature of the growth-limiting substrate. The significance of these changes in terms of metabolic regulation and economy of enzyme synthesis is discussed.

\section{INTRODUCTION}

With the introduction and development of techniques for the continuous cultivation of micro-organisms (Monod, 1950; Novick \& Szilard, 1950; Herbert, Elsworth \& Telling, 1956), it is possible to study the influence of specific environmental changes on the chemical composition and metabolic activity of micro-organisms under conditions where the physical and chemical environment is rigidly controlled. Much data have accumulated on the variations in chemical composition and in macromolecular organization of organisms which occur when specific changes in environment are made; for example in intracellular polysaccharide content (Holme, 1957), in RNA content (Neidhardt \& Magasanik, 1960; Dean, 1962; Rosset, Monier \& Julien, 1964), ribosomal composition and content (Ecker \& Schaechter, 1963; Sykes \& Tempest, 1965; Tempest, Hunter \& Sykes, 1965; Tempest \& Hunter, 1965) and in cell wall composition and content (Collins, 1964; Sud \& Schaechter, 1964). The present paper reports results of experiments designed to determine whether quantitative changes in some 'constitutive' enzyme systems can occur.

In C-limited cultures the carbon-containing substrate is present in the environment at a concentration which is insufficient to saturate the oxidative enzymes of the organisms (see Herbert et al. 1956). It follows, therefore, that the changes in substrate oxidation rate which accompany changes in 'steady state' growth rate need not necessarily require similar changes in cellular oxidative enzyme concentration but could result solely from changes in the degree of subsaturation of a constant amount of enzymic material. A measure of cellular oxidative enzyme concentration can be obtained from the rates of oxidation of excess substrate by washed suspensions of organisms prepared from chemostat-grown cultures. We report here the rates of oxidation of glucose, xylose and ethanol by Torula utilis organisms grown at various dilution rates in glucose-, xylose-, ethanol- and $\mathrm{NH}_{4}{ }^{+}$-limited environments. 


\section{METHODS}

Organism. Torula utilis (NCYC 321) maintained by fortnightly subculture on a medium containing $(\% \mathrm{w} / \mathrm{v}): \mathbf{0 . 3}$ yeast extract, 0.5 peptone, 1 glucose, 0.2 potassium dihydrogen phosphate, 2 agar; $\mathrm{pH} 5 \cdot 5$.

Media. The carbon-limited media contained: $\left(\mathrm{NH}_{4}\right)_{2} \mathrm{SO}_{4}, 0 \cdot 15 \mathrm{M} ; \mathrm{KH}_{2} \mathrm{PO}_{4}$, $5 \times 10^{-2} \mathrm{M}$; citric acid, $4 \times 10^{-3} \mathrm{M}$; biotin, $1 \times 10^{-7} \mathrm{M} ; \mathrm{MgCl}_{2}, 1.25 \times 10^{-3} \mathrm{M}$; traces of $\mathrm{Ca}^{2+}, \mathrm{Fe}^{3+}, \mathrm{Zn}^{2+}, \mathrm{Mn}^{2+}, \mathrm{Cu}^{2+}, \mathrm{Co}^{2+}, \mathrm{MoO}_{4}{ }^{2-}$; the carbon source was added to a final concentration of $1 \%(\mathrm{w} / \mathrm{v})$. To obtain $\mathrm{NH}_{4}{ }^{+}$-limited conditions $\left(\mathrm{NH}_{4}\right)_{2} \mathrm{SO}_{4}$ was reduced to $\left(1.8 \times 10^{-2} \mathrm{M}\right)$ and glucose was increased to $5 \%(\mathrm{w} / \mathrm{v})$.

Apparatus. A chemostat of $0.5 \mathrm{l}$. working volume, with automatic $\mathrm{pH}$ control, which permitted the growth of organisms to a high concentration, was used. Temperature was automatically controlled at $30^{\circ}$, and the $\mathrm{pH}$ value at $5 \cdot 5$.

Dry weights. Duplicate samples of culture $(5 \mathrm{ml}$.) were centrifuged $(3000 \mathrm{~g}$ for $10 \mathrm{~min}$.) in weighed $100 \mathrm{~mm} . \times 12 \mathrm{~mm}$. Pyrex tubes; the organisms were washed in distilled water by centrifugation and dried at $105^{\circ}$ for $16 \mathrm{hr}$. Results for duplicate samples were within $5 \%$, and generally within $2 \%$, of each other.

Protein. The method of Stickland (1951) was used; a standard was provided by a solution of bovine plasma albumin (Armour Laboratories Ltd.).

Determination of culture $Q_{\mathrm{o}_{2}}$ values. These are reported as $\mu$ l. oxygen uptake/mg. protein $/ \mathrm{hr}$ and were calculated from the rates of air flow through the chemostat oxygen content of the effluent air (determined with a Beckman Model E-2 oxygen analyser), culture dry weight of organisms and their protein contents. It was necessary to base oxygen uptake rates on culture protein content because of the gross variations in polysaccharide content and hence of the dry weight of organisms grown in the $\mathbf{N H}_{4}{ }^{+}$-limited medium.

Determination of $Q_{0_{2}}$ values of washed suspensions. These were determined by the conventional manometric technique. Each manometer vessel contained substrate $(0 \cdot 1 \mathrm{ml} .1 \mathrm{M}$; in the side-arm) and approximately $2 \mathrm{mg}$. dry weight organisms, suspended in $1.9 \mathrm{ml} .0 .06 \mathrm{M}$-phosphate buffer $(\mathrm{pH} \mathrm{5.5)}$ in the main compartment; $0.2 \mathrm{ml} .3 \mathrm{~N}-\mathrm{NaOH}$, and a pleated square of filter paper, was placed in the centre well. Temperature was adjusted to $30^{\circ}$ and the oxygen uptake followed for $60 \mathrm{~min}$. after mixing the contents of the side-bulb and main compartment. The oxygen uptake rates were linear over the period of observation; endogenous respiration rates (simultaneously measured) were subtracted from the substrate oxidation rates.

Experimental procedure. Organisms from an overnight culture grown on the maintenance medium were inoculated into the selected medium contained in the chemostat. After growth had ceased, a regulated flow of fresh medium to the culture was started. The medium flow rate was initially adjusted to $0.1 \mathrm{vol} / \mathrm{hr}$ and the culture left to equilibrate for 2-3 days before the start of each experiment. After this period a sample $(50 \mathrm{ml}$.) of culture was removed from the chemostat, cooled to $4^{\circ}$ and used for dry-weight determination $(2 \times 5 \mathrm{ml}$.) for metabolic studies $(10 \mathrm{ml}$.) and for chemical analysis of organisms $(30 \mathrm{ml}$. washed in distilled water and lyophilized). The flow rate of medium was then changed to a new value, the culture left to equilibrate for 2 days, and the above procedure repeated. The flow rate was progressively increased until the 'critical' dilution rate was reached; the flow rate 
was then progressively decreased in similar increments to a suitable minimum value (usually 0.05 vol./hr). Each experiment took 3-4 weeks to complete, and successively employed glucose-, xylose-, ethanol-, and $\mathrm{NH}_{4}{ }^{+}-$limited conditions.

\section{RESULTS}

\section{Effect of growth rate on respiration rate of Torula utilis cultures}

When growth is limited by the supply of carbon source the rate of oxygen uptake will depend on the dilution rate. The relationship between respiration rate and growth rate in cultures of Torula utilis growing in either a xylose-limited or an ethanol-limited medium was linear (Fig. 1). At zero growth rate neither plot passes through the origin but extrapolates back to a finite $Q_{o_{2}}$ value which probably represents the endogenous respiration rate (see similar result with Aerobacter aerogenes culture; Herbert, 1958). Under nitrogen-limited conditions with excess carbon source, a similar result was obtained (Fig. 2) but here the extrapolated $Q_{\mathrm{O}_{2}}$ value was much higher since it included not only the endogenous respiration but also the oxidation of glucose in the absence of utilizable nitrogen. The rates of endogenous metabolism were dependent on growth rate with both $\mathrm{C}$ - and $\mathrm{N}$-limited organisms (Fig. 3) though in different ways. The increase in endogenous metabolism at low growth rates in $\mathbf{N}$-limited organisms correlated with a gross increase in intracellular glycogen-like material (Herbert, 1961).

\section{Effect of growth rate on the metabolic activity of Torula utilis organisms}

To grow at any specific rate the organisms must oxidize the carbon source at a corresponding minimum rate; in $\mathrm{C}$-limited cultures however the capacity to oxidize the substrate may be much greater than the rate required to sustain growth. This was apparent with the glucose oxidizing system of Torula utilis organisms grown at a low dilution rate in a glucose-limited medium (compare Figs. 2 and 4). In Fig. 4 it is apparent that the oxidative ability of glucose-limited organisms varied little with growth rate and that differences in substrate dissimilation rates, in the culture, resulted from changes in the degree of saturation of enzymes on changing the substrate input rate. In contrast, the xylose oxidizing system of xylose-limited organisms varied markedly with growth rate (Fig. 5) in a manner which paralleled the changes in culture respiration rate (Fig. 1). The enzyme system oxidizing ethanol in ethanol-limited organisms responded in a different manner to changes in dilution rate (Fig. 5) in that it varied only slightly between dilution rates of 0.05 and 0.35 vol./hr but then markedly at higher growth rates.

In chemostat cultures a simple relationship between specific growth rate and the concentration of growth-limiting substrate has been demonstrated (Monod, 1942, Herbert et al. 1956); it seems likely therefore, that changes in the oxidative capacity, of C-limited organisms are due primarily to changes in intracellular substrate concentration which influence mechanisms controlling enzyme synthesis. In $\mathrm{N}$-limited cultures, where the carbon-containing substrate concentration is independent of growth rate, a direct relationship between substrate oxidizing capacity and dilution rate would not be expected. However it is apparent (Fig. 6) that the glucose oxidizing ability of $\mathrm{N}$-limited Torula utilis organisms (carbon source, glucose) did vary markedly with growth rate, and to a greater extent than that of glucose-limited 


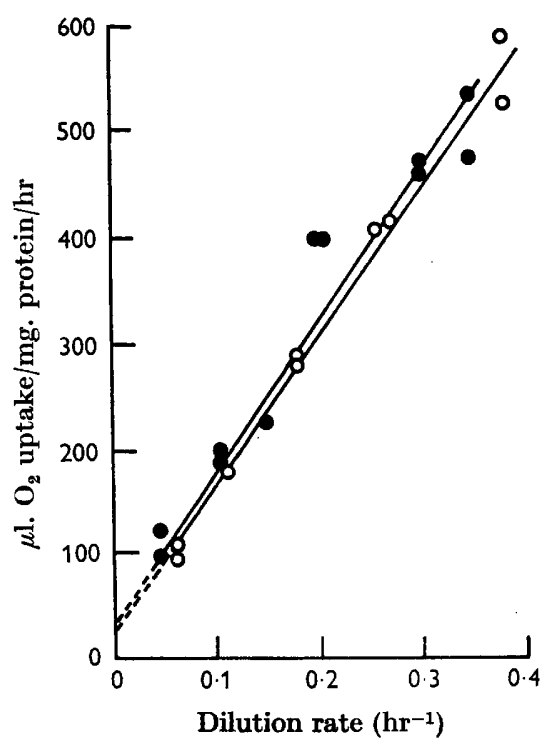

Fig. 1

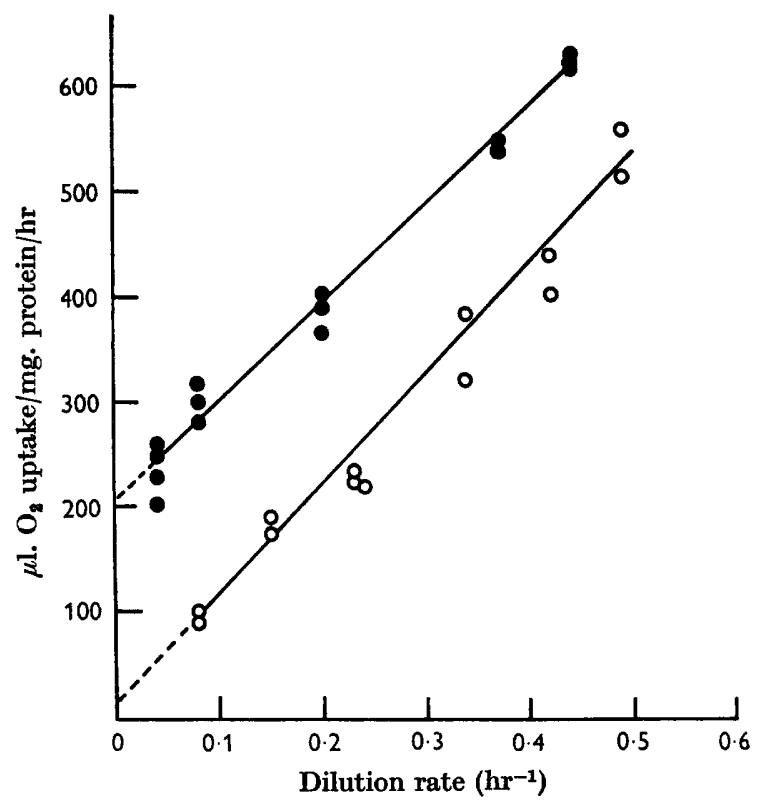

Fig. 2

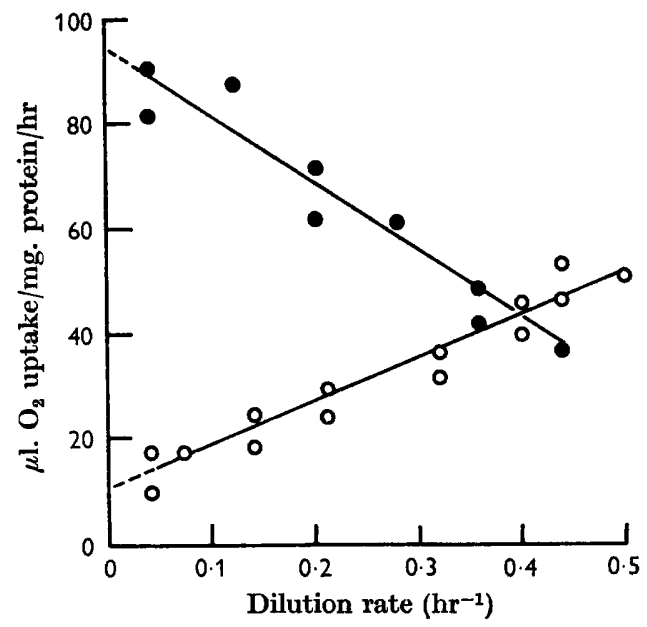

Fig. 3

Fig. 1. Rates of oxygen uptake ( $\mu \mathrm{l} . / \mathrm{mg}$. protein/hr) by Torula utilis organisms growing in xylose-limited $(O)$ and ethanol-limited $(O)$ media at several dilution rates.

Fig. 2. Rates of oxygen uptake ( $\mu \mathrm{l} . / \mathrm{mg}$. protein $/ \mathrm{hr}$ ) by $T$. utilis organisms growing in a glucose medium $\mathrm{NH}_{4}+$-limited $(0)$ and C-limited $(0)$.

Fig. 8. Rates of endogenous respiration ( $\mu \mathrm{l} . / \mathrm{mg}$. protein/hr) of NH-limited (O) and $\mathrm{C}$-limited (O) $T$. utilis organisms grown at several dilution rates, washed free from the culture medium and suspended in $0.06 \mathrm{M}-$ phosphate buffer (pH 5.5). 


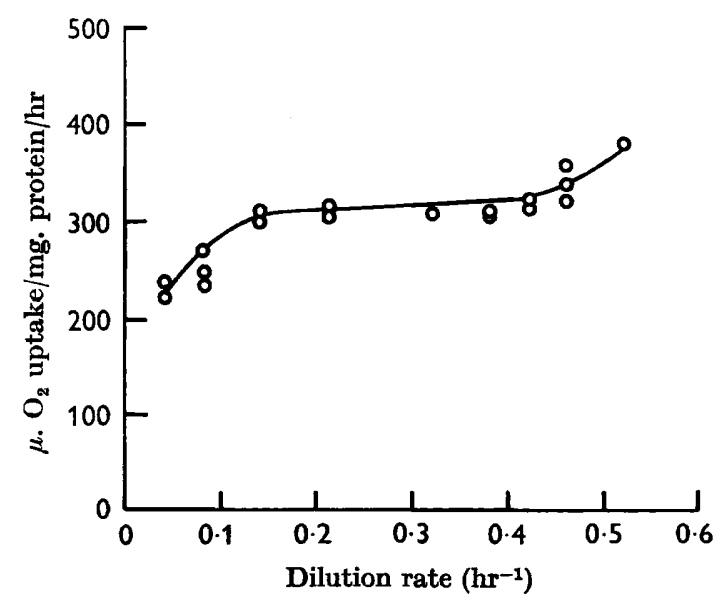

Fig. 4

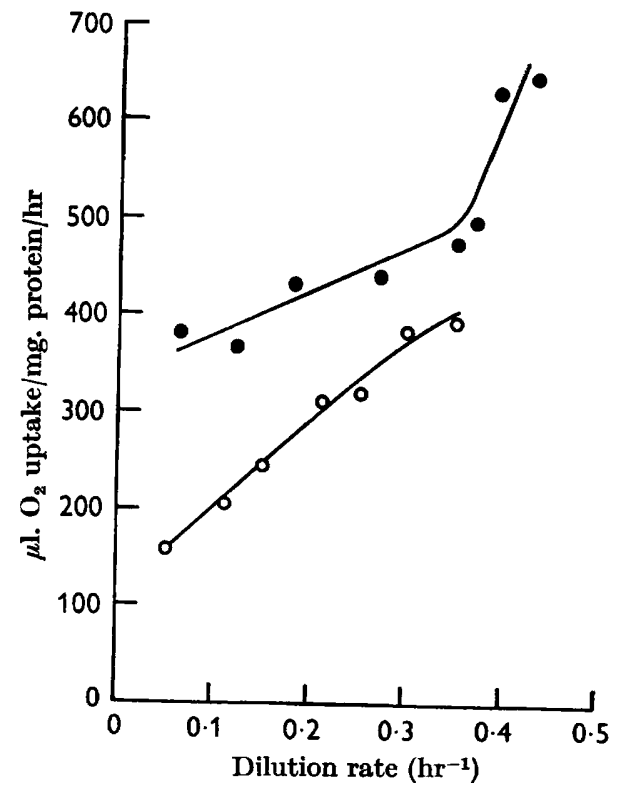

Fig. 5

Fig. 4. Rates of oxidation ( $\mu \mathrm{l}$./mg. protein $/ \mathrm{hr}$ ) of $50 \mathrm{~mm}$-glucose by washed suspensions of $\mathrm{C}$ (glucose)-limited $T$. utilis organisms grown at several dilution rates; endogenous values subtracted.

Fig. 5. Rates of oxidation ( $\mu \mathrm{l} . / \mathrm{mg}$. protein/hr) of 50 mm-ethanol by C (ethanol)-limited (O), and $50 \mathrm{~mm}$-xylose by $\mathrm{C}$ (xylose)-limited (O) $T$. utilis organisms, grown at several dilution rates; endogenous values subtracted.

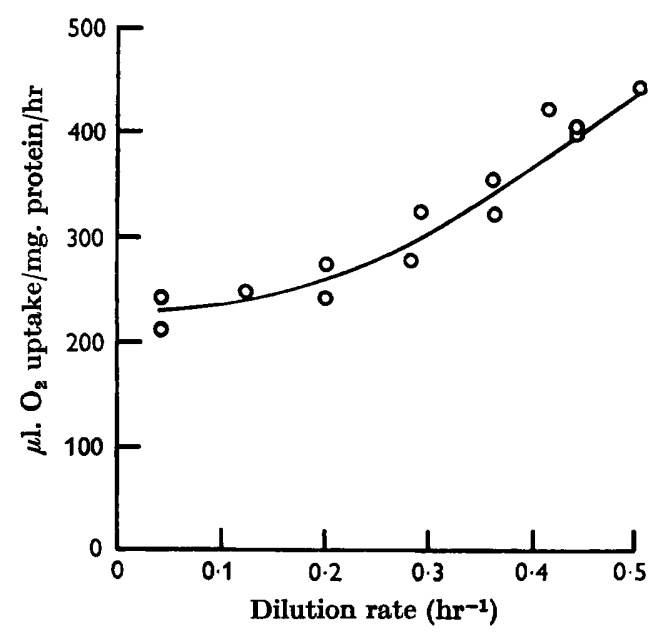

Fig. 6

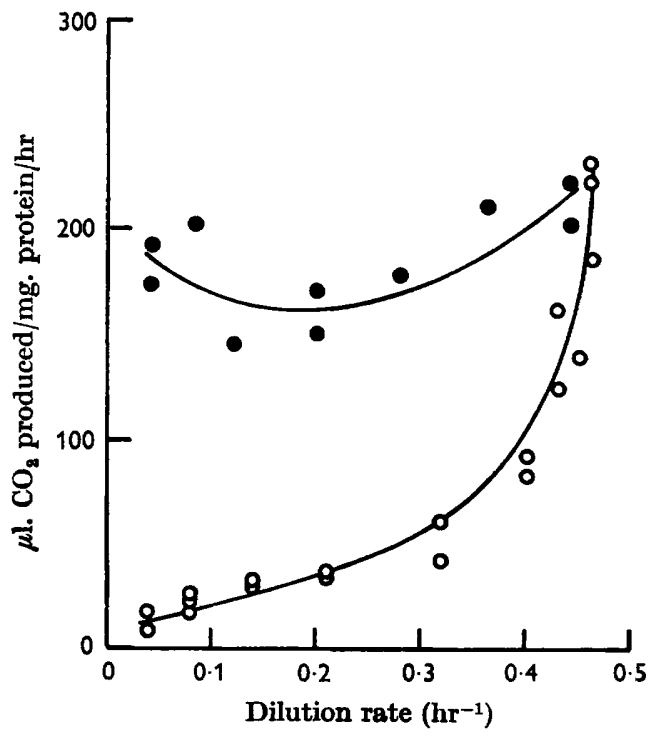

Fig. 7

Fig. 6. Rates of oxidation ( $\mu \mathrm{l} . / \mathrm{mg}$. protein $/ \mathrm{hr}$ ) of $50 \mathrm{~mm}$-glucose by washed suspensions of $\mathrm{NH}_{4}+$-limited $\mathrm{T}$. utilis organisms grown at several dilution rates; endogenous values subtracted.

Fig. 7. Rates of fermentation ( $\mu \mathrm{l} . \mathrm{CO}_{2}$ produced/mg. protein/hr) of $50 \mathrm{~mm}$-glucose by $\mathrm{NH}_{4}{ }^{+}$-limited (O) and $\mathrm{C}$ (glucose)-limited (O) $T$. utilis organisms grown at several dilution rates; endogenous values subtracted. 
organisms (Fig. 4). Changes in the ability of glucose-grown organisms to dissimilate glucose anaerobically accompanied changes in their oxidative capacity. Here (Fig. 7) fermentative capacity correlated with the concentration of glucose in the culture, indicating an inductive synthesis of the enzyme(s).

\section{Changes in the ability of Torula utilis organisms to oxidize compounds other than the growth substrate}

The rate at which washed suspensions of organisms oxidized a substrate varied not only when organisms were grown at different rates in a medium containing that substrate, but also when they were grown in media containing other compounds.

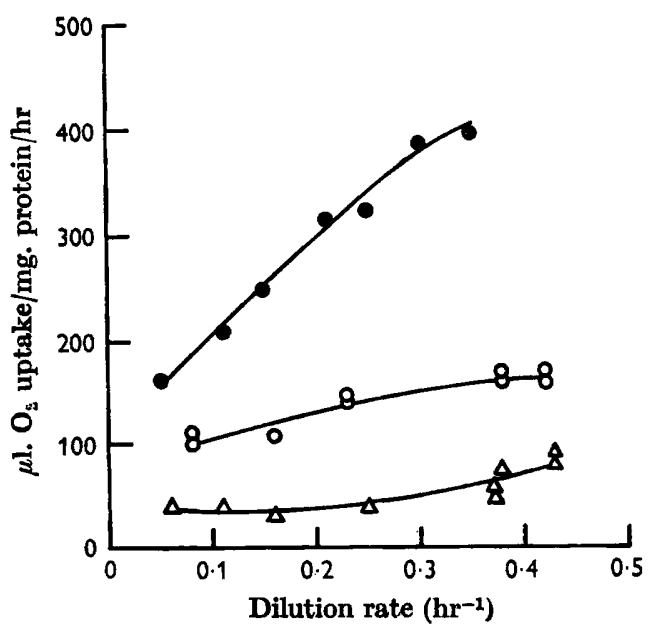

Fig. 8

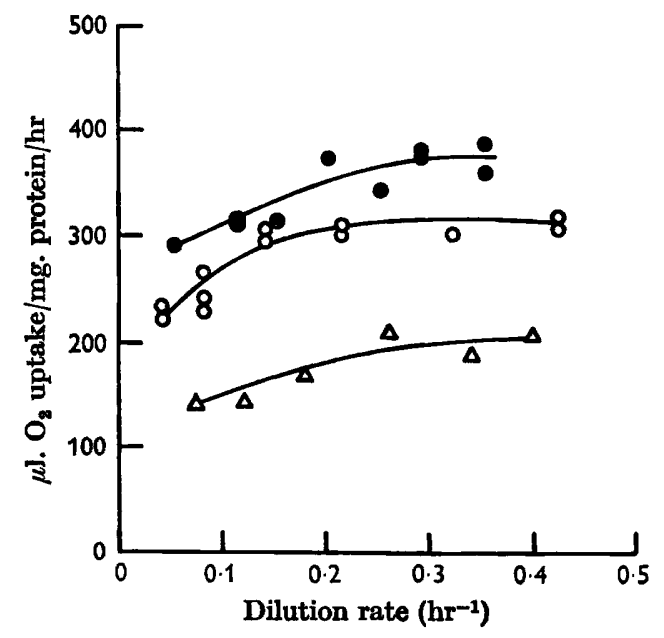

Fig. 9

Fig. 8. Rates of oxidation ( $\mu \mathrm{l} . / \mathrm{mg}$. protein/hr) of $50 \mathrm{~mm}$ xylose by washed suspensions of $T$. utilis organisms grown on an xylose-limited medium (O), a glucose-limited medium $(O)$ and an ethanol-limited medium $(\Delta)$ at several dilution rates; endogenous values subtracted.

Fig. 9. Rates of oxidation ( $\mu \mathrm{l} . / \mathrm{mg}$. protein $/ \mathrm{hr}$ ) of $50 \mathrm{~mm}$ glucose by washed suspensions of $T$. utilis organisms grown on a xylose-limited $(O)$, a glucose-limited $(O)$ and an ethanollimited $(\triangle)$ medium at several dilution rates; endogenous values subtracted.

Comparison of the rates of xylose oxidation by xylose-, glucose- and ethanollimited organisms showed (Fig. 8) that at each dilution rate xylose-grown organisms had a greater xylose oxidizing capacity than glucose-grown organisms, and that the latter were able to oxidize this substrate more readily than were ethanol-grown organisms. In contrast to this observation it was found (Fig. 9) that glucose was oxidized more rapidly by xylose-grown organisms than by glucose-grown organisms, though again ethanol-grown organisms had a much lower glucose oxidizing capacity.

\section{DISCUSSION}

Although oxidation of a substrate is a multi-enzyme process, the overall rate must be a function of a single rate-limiting reaction in the chain of reactions which starts with the permeation of substrate into the organism and terminates with its oxidation 
and assimilation. It seems reasonable to assume that in our experiments such a rate-limiting step was not located on that part of the oxidation pathway which was common to all three substrates (e.g. the tricarboxylic acid cycle or the electron transport system), otherwise a common pattern of change in oxidative capacity with dilution rate would have resulted and this was not observed. Data derived from studies on isolated enzymes (see Gorini \& Maas, 1957) would have provided definite results, assuming that the specific rate-limiting reactions were known, but as a first approach the results obtained with washed suspensions of organisms are uggestive. Comparing the $Q_{\mathrm{O}_{2}}$ values of the growing cultures, which represent their 'oxidative demands' (Figs. 1, 2), with corresponding $\mathbf{Q}_{\mathrm{O}_{2}}$ values of washed suspensions of organisms (Figs. 4-6), which represent their 'oxidative capacities', it is evident that in most cases a decrease in growth rate caused a decrease in both values, indicating an economy in enzyme synthesis. This economy was not apparent in the glucose-limited culture (Fig. 4) but was observed in the corresponding N-limited culture (Fig. 6), where glucose was present in excess of requirement in the environment. The reasons for this difference are not obvious, but may reflect the differing metabolic priorities when protein synthesis is limited by the energy supply as opposed to the supply of a structural element.

The oxidative enzyme systems of Torula utilis investigated here are 'constitutively' produced and yet there appeared to have been considerable variations in their rates of synthesis which suggest that the mechanisms controlling their biosynthesis were quantitatively rather than qualitatively different from those which controlled 'adaptive' enzyme synthesis. The differing abilities of glucose-, xylose- and ethanollimited organisms to oxidize xylose (Fig. 8) emphasize the quantitative nature of the mechanisms which control 'constitutive' enzyme synthesis; they also reflect the degrees of similarity between the three oxidative pathways. In this connexion the enhanced rate of glucose oxidation by xylose-limited organisms (Fig. 9) may have resulted from glucose being preferentially oxidized via the 'pentose phosphate cycle'. Blumenthal, Lewis \& Weinhouse (1954) showed that this pathway and the 'glycolytic' pathway of glucose catabolism were operative in T. utilis; growth on xylose causes, presumably, increased synthesis of enzymes of the pentose phosphate cycle.

It is possible that the observed changes in oxidative capacity of organisms resulted from variations in the rate of substrate permeation into the organisms, though this seems unlikely, since substrate oxidation, by washed suspensions of organisms, occurred without a lag and was linear for at least an hour. Thus it seems that growth rate and growth-limiting substrate affect not only the composition of organisms (Herbert, 1961; Neidhardt, 1963) but also their metabolic activity.

\section{REFERENCES}

Blumenthal, H. J., Lewis, K. F. \& Weinhouse, S. (1954). An estimation of pathways of glucose catabolism in yeast. $J . A m$. chem. Soc. 76, 6093.

Collins, F. M. (1964). The effect of growth rate on the composition of Salmonella enteritidis cell walls. Aust. J. exp. Biol. med. Sci. 42, 255.

DEan, A. C. R. (1962). Nucleic acid and protein content of Bact. lactis aerogenes. I. Equilibrium and non-equilibrium conditions. Proc. Roy. Soc. B, 155, 580.

Ecker, R. E. \& Schaechter, M. (1963). Ribosome content and the growth of Salmonella typhimurium. Biochim. biophys. Acta, 76, 275. 
GorinI, L. \& MAAS, W. K. (1857). The potential for the formation of a biosynthetic enzyme in Escherichia coli. Biochim. Biophys. Acta, 25, 208.

Herbert, D. (1958). Some principles of continuous culture. In Recent Progress in Microbiology, VII Int. Congr. Microbiol. p. 381.

Herbert, D. (1961). The chemical composition of micro-organisms as a function of their environment. In Microbial Reaction to Environment. Symp. Soc. gen. Microbiol., 11, 391.

Herbert, D., Elsworth, R. \& Telling, R. C. (1956). The continuous culture of bacteria; a theoretical and experimental study. J. gen. Microbiol. 14, 601 .

HoLme, T. (1957). Continuous culture studies on glycogen synthesis in Escherichia coli B. Acta chem. scand. 11, 763.

MonoD, J. (1942). Recherches sur la croissance des cultures bacteriennes. Paris: Hermann \& Cie.

Monod, J. (1950). La technique de culture continué; theorie et applications. Ann. Inst. Pasteur, 79, 390.

NeIdHaRdT, F. C. (1963). Effect of environment on the composition of bacterial cells. Annu. Rev. Microbiol. 17, 61.

Neidhart, F. C. \& Magasanik, B. (1960). Studies on the role of ribonucleic acid in the growth of bacteria. Biochim. biophys. Acta, $42,99$.

Novick, A. \& Szilard, L. (1950). Description of the chemostat. Science, 112, 715.

Rosset, P., Monier, R. \& Julien, J. (1964). RNA composition of Escherichia coli as a function of growth rate. Biochem. biophys. Res. Commun. 15, 329.

STICKLAND, L. H. (1951). The determination of small quantities of bacteria by means of the biuret reaction. J. gen. Microbiol. 5, 698.

Sud, I. J. \& Schaechter, M. (1964). Dependence of the content of cell envelopes on the growth rate of Bacillus megatherium. J. Bact. 88, 1612.

Sykes, J. \& Tempest, D. W. (1965). The effect of magnesium and of carbon limitation on the macromolecular organisation and metabolic activity of Pseudomonas sp., strain c-1 B. Biochim. biophys. Acta, 103, 93.

Tempest, D. W. \& HunTER, J. R. (1965). Influence of temperature on the macromolecular composition of $\mathrm{c}$ (glycerol)-limited and $\mathrm{Mg}^{2+}$-limited Aerobacter aerogenes, growing in a chemostat. J. gen. Microbiol. (Vol. 41, in the Press).

'Tempest, D. W., Hunter, J. R. \& Sykes, J. (1965). Magnesium-limited growth of Aerobacter aerogenes in a chemostat. J. gen. Microbiol. 39, 355. 